\title{
Antiplasmodial Lycorane Alkaloid Principles of the Plant Family Amaryllidaceae
}

Authors

Jerald J. Nair, Johannes van Staden

\begin{abstract}
Affiliation
Research Centre for Plant Growth and Development, University of KwaZulu-Natal Pietermaritzburg, Scottsville, South Africa
\end{abstract}

Key words

alkaloid, amaryllidaceae, antiplasmodial, malaria, medicinal plant

received January 17, 2019

revised March 12, 2019

accepted March 14, 2019

Bibliography

DOI https://doi.org/10.1055/a-0880-5414

Published online March 25, 2019 | Planta Med 2019; 85: 637647 c Georg Thieme Verlag KG Stuttgart · New York I ISSN 0032-0943

Correspondence

Prof. Johannes van Staden

Research Centre for Plant Growth and Development, School of Life Sciences, University of KwaZulu-Natal Pietermaritzburg

Private Bag X01, Scottsville, 3209 Pietermaritzburg, South Africa

Phone: + 27332605130 , Fax: + 27332605897

rcpgd@ukzn.ac.za

\section{ABSTRACT}

The spread of malaria is thought to have followed human expansion out of Africa some 60-80 thousand years ago. With its prevalence in pantropical countries of the world and epicenter localized in Africa, malaria is now considered an unnecessary burden to overworked and under-resourced healthcare structures. Plants have long afforded a fertile hunting ground for the search and identification of structurally diverse antimalarial agents, such as quinine and artemisinin. This survey examines the antiparasitic properties of the family Amaryllidaceae via the antiplasmodial activities demonstrated for its lycorane alkaloid principles. Of these, 24 were natural compounds identified in 20 species from 11 genera of the Amaryllidaceae family, whilst the remaining 28 were synthetically derived entities based on the lycorane skeleton. These were screened against ten different strains of the malarial parasite Plasmodium falciparum, wherein the parent compound lycorine was shown to be the most potent with an $\mathrm{IC}_{50}$ of $0.029 \mu \mathrm{g} / \mathrm{mL}$ in the FCR-3 strain seen to be the best. Structure-activity relationship studies revealed that good activities were detectable across both the natural compounds as well as the synthetically accessed derivatives. Such studies also highlighted that there are several inherent structural features that define the lycorane alkaloid antiplasmodial pharmacophore, such as the nature of its ring systems and properties of its substituents. Mechanistically, a limited number of studies confirmed that lycorane alkaloids manifest their action by targeting enzymes associated with the plasmodial FAS-II biosynthetic pathways. Overall, these alkaloids have provided useful, convenient, and accessible scaffolds for antimalarial-based drug discovery.

$\begin{array}{ll}\text { ABBREVIATIONS } \\ \text { ED } & \text { effective dose } \\ \text { EtOH } & \text { ethanol } \\ \text { IC } & \text { inhibitory concentration } \\ \text { MeOH } & \text { methanol } \\ \text { SI } & \text { selectivity index } \\ \text { TM } & \text { traditional medicine } \\ \text { WHO } & \text { World Health Organization }\end{array}$

\section{Introduction}

Despite the implementation of intensive prevention, control, and treatment strategies by world health bodies such as the WHO, malaria continues to be a burden to healthcare structures, particularly in tropical and subtropical regions of the world [1]. There were over 200 million cases of malaria in 2017 , $90 \%$ of which occurred in Africa, mainly in its sub-Saharan region [1]. Over 400000 deaths from malaria were recorded during 2017, again mostly on the African continent [1]. Although global incidence rates have diminished by as much as 18\% between 2010 and 2017, substantial 
increases were unexpectedly realized during this period for several countries in the Americas [1]. Around US $\$ 3$ billion worth of investment in 2017 alone was channelled towards programs across disciplines involved in the struggle against malaria [1]. The areas funded, amongst others, included studies on (i) the insect vector and insect resistance, (ii) insecticides, (iii) the pathogen and pathogen resistance, (iv) bioengineering, (v) the search for new drugs, (vi) multidrug resistance, (vii) development of vaccines, (viii) infection, and (ix) epidemiology [1].

Malaria is caused by a group of parasitic protozoans belonging to the genus Plasmodium [2]. Although there are over one hundred species of Plasmodium, five, including Plasmodium falciparum, Plasmodium malariae, Plasmodium ovale, Plasmodium vivax, and Plasmodium knowlesi, are known to cause infections in humans [3]. P. falciparum is the chief malaria-causing pathogen in humans [3]. It is transmitted by various insect vectors, but mainly by representatives of the mosquito genus Anopheles such as Anopheles gambiae [3]. Requiring both insect and vertebrate hosts to survive, following the initial mosquito bite, the pathogen can remain sequestered as an hypnozoite for several months in the liver or other host tissue, or become active as a merozoite once infection sets in [3]. These then pass from liver cells into the blood where they undergo continuous cycles of erythrocytic infection, passing from the trophozoite and schizontic stages into new merozoites, at which point the cell bursts, releasing these bodies to repeat the infection cycle [3]. Other merozoites can also develop into mature gametocytes that are taken up with the blood following a bite from a fertilized female mosquito [3]. These then mature in the insect gut, where male and female gametocytes also fuse to form ookinetes, which differentiate into new sporozoites that migrate to the salivary glands of the bug in advance of the first step of the infection process [3].

There has been a long and close involvement of plants in traditional systems of medicine associated with the remediation of malaria [4]. In fact, well over 1000 individual plant taxa from various regions around the globe have been ratified with such particular functions in TM [4]. These have led to the discovery of life-saving medications such as quinine and artemisinin, which subsequently set the stage for the advent of the modern day antimalarial drug discovery initiative $[2,5]$. As a consequence, commercial drugs such as chloroquine and mefloquine, which have loosely been modelled on the active quinine pharmacophore, served to perpetuate discovery efforts in the synthesis-based sector [5]. There has also been significant interest in the vaccine development arena, although a commercially viable product is still to reach the market [2]. This, together with the progressive loss of efficacies of contemporary drugs as well as multidrug resistance, has contributed towards the resurgence in the identification and development of new antimalarial drugs [2]. There are several factors to vindicate the obvious choice of plants in such endeavors, including evidence-based prevalence in TM, natural abundance with only about $10 \%$ of known species to date being examined for possible therapeutic benefits, and an inimitably wide chemical constitution running into several hundred thousands of individual structures [6, 7].

The bulbous flowering plant family Amaryllidaceae is recognizable for its unique chemical character, due primarily to its isoqui- noline alkaloid constituents [8]. Apart from their significant array of structural diversity, these alkaloids are also characterized by a wide range of biological properties, particularly in the cancer and motor neuron disease arenas [9]. In the microbial area, promising antibacterial and antifungal activities have been described for several members of the family $[10,11]$. The lycorine alkaloids are the largest of the nine alkaloid groups discernible for the Amaryllidaceae [8]. Biologically, they have shown the most promise as potential anticancer agents [12]. This survey examines the antiparasitic properties of the Amaryllidaceae via the antiplasmodial activities described for its lycorane alkaloid constituents. It covers the activities of both natural compounds isolated from the various species of the family as well as their semisynthetically accessed derivatives against different strains of the malaria pathogen $P$. falciparum. Also considered are structure-activity relationship studies that have sought to improve activities as well as to grasp the underlying elements of the lycorane antiplasmodial pharmacophore.

\section{Crinum L.}

With around 150 known species, Crinum is one of the largest genera of the Amaryllidaceae [13]. Nearly 30 of its members are found with a fairly wide distribution in South Africa [13]. It holds the distinction of affording the first alkaloid constituents of the family that were studied for antiplasmodial effects [14]. In this regard, phytochemical studies were carried out on ethanolic extracts of Crinum amabile Donn ex Ker Gawl. from a bulb collection made in Bangkok, Thailand, accompanied by antiplasmodial activity screening [14]. The parent compound lycorine (1) (• Fig. 1) was identified via spectroscopic means including 2D NMR data analysis and thereafter subjected to a screen against the chloroquine-sensitive and chloroquine-resistant $P$. falciparum strains $D$ 6 and $W-2$, respectively [14]. It exhibited similar activities in both plasmodial strains with $E_{50}$ of 0.32 and $0.30 \mu \mathrm{g} / \mathrm{mL}$, respectively [14]. In order to establish whether this effect was due to direct antiplasmodial effects rather than to cellular toxicity, lycorine was concurrently also screened against the human oral epidermoid KB cell line, where it exhibited an $\mathrm{ED}_{50}$ of $0.30 \mu \mathrm{g} / \mathrm{mL}$ [14]. The SI of 1 for lycorine, taking these values into consideration, was dwarfed in comparison to those calculated for artemisinin (SIs > 33300 and > 40000 in both strains, respectively) [14]. Lycorine has also been described in bulbs of the popular South African medicinal plants Crinum macowanii Baker and Crinum bulbispermum (Burm.f.) Milne-Redh. \& Schweick., respectively $[15,16]$. In the first instance, it was shown to be active against the $P$. falciparum chloroquine-sensitive strain NF54 (IC 50 of $0.34 \mu \mathrm{g} / \mathrm{mL})$ [15]. In the latter case, lycorine proved to be over ten times more active against the resistant Gambian FCR-3 strain of $P$. falciparum $\left(\mathrm{IC}_{50}\right.$ of $0.029 \mu \mathrm{g} / \mathrm{mL}$ ) [16]. Two Kenyan Crinum species then became the focus of studies in search of potential antiprotozoal bulb alkaloid constituents $[17,18]$. In the first instance, none of the three lycorane alkaloids identified in Crinum stuhlmannii Baker, including lycorine (1), kirkine (2), and 9-O-demethylpluviine (3), exhibited any activities towards the NF54 strain [17]. Likewise, none of the lycorane alkaloids present in Crinum kirkii Baker, in spite of their significant structural variation, were able to inhibit the in vitro 

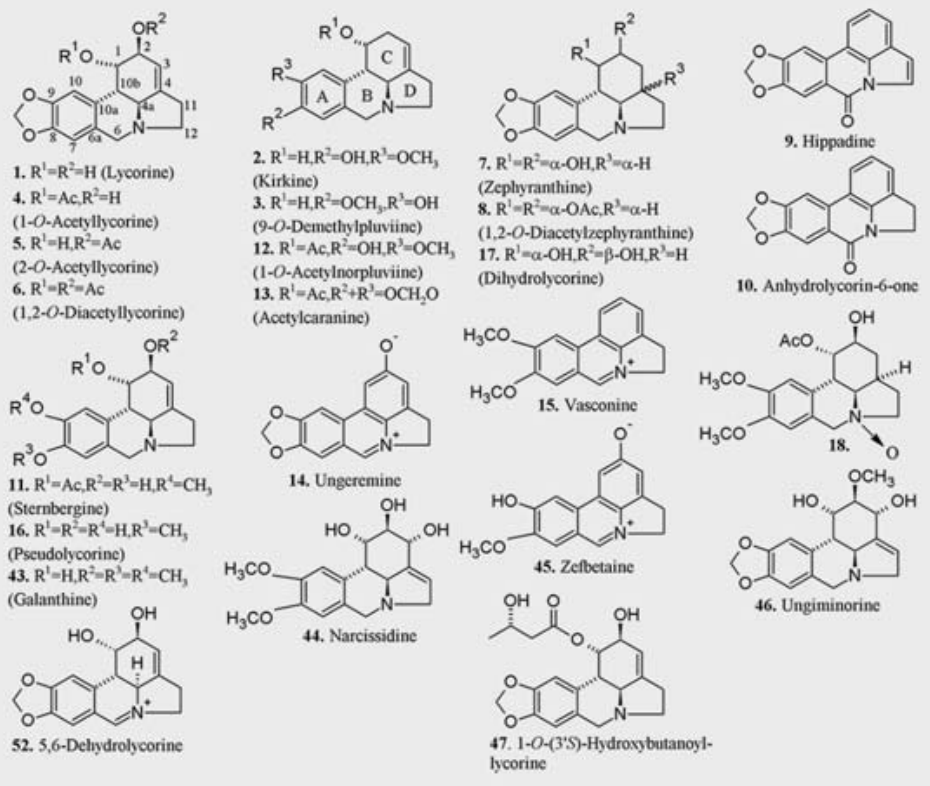

- Fig. 1 Natural lycorane alkaloids of the Amaryllidaceae that have been examined for antiplasmodial effects.

growth of either chloroquine-sensitive (NF54) or chloroquine-resistant (K1) strains of $P$. falciparum [18]. These seven compounds were identified as lycorine (1), kirkine (2), 1-O-acetyllycorine (4), 2-0-acetyllycorine (5), 1,2-0-diacetyllycorine (6), zephyranthine (7), and 1,2-0-diacetylzephyranthine (8) [18]. The lack of activity for lycorine in these two studies is noteworthy given that it had, in the interim, been shown to be active against the NF54 strain [15]. Crinum erubescens L.f. ex Aiton was the topic of the remaining antiplasmodial study carried out on the genus Crinum [19]. In the event, the anhydro-lycorane analog hippadine (9) proved to be inactive against the chloroquine/mefloquine-resistant $\operatorname{Dd} 2$ strain when tested at a concentration as high as $38 \mu \mathrm{M}$ [19].

\section{Brunsvigia Heist.}

The genus Brunsvigia is a true representative of the South African indigenous flora, with a distribution that is restricted to the winter rainfall region of the Western Cape Province [13]. It, together with Amaryllis L., Boophone Herb., Crinum L., Nerine Herb., and Strumaria Jacq., constitute the African tribe Amaryllideae of the Amaryllidaceae [13]. Some of its members are known to be used in the TM of the indigenous people of the region $[20,21]$. The two species examined for antimalarial effects were Brunsvigia littoralis R. A.Dyer and Brunsvigia radulosa Herb. [22,23]. Lycorine (1) and 1,2-O-diacetyllycorine (6) were the two lycorane alkaloids identified in $B$. littoralis and subsequently screened against the $P$. falciparum sensitive and resistant strains D10 and FAC8, respectively [22]. In these instances, lycorine was shown to be more active $\left(\mathrm{IC}_{50} \mathrm{~S}\right.$ of 0.62 and $0.70 \mu \mathrm{g} / \mathrm{mL}$, respectively) compared to the latter $\left(\mathrm{IC}_{50}\right.$ of $1.0 \mathrm{\mu g} / \mathrm{mL}$ in each case) ( $\triangleright$ Table 1$)$ [22]. The selectivity index of $\sim 3$ for lycorine measured against its cytotoxicity in BL6 mouse melanoma cells ( $\mathrm{IC}_{50}$ of $\left.1.8 \mu \mathrm{g} / \mathrm{mL}\right)$ again favored its antiplasmodial activity, although this value was orders of magnitude less than that calculated for artemisinin ( $>25000$ and $>5000$, respectively) [22]. The phytochemical analysis of $B$. radulosa yielded the four lycorane alkaloids lycorine (1), anhydrolycorin-6-one (10), sternbergine (11), and 1-O-acetylnorpluviine (12) [23]. As in the previous study by the same authors [22], the alkaloids were also subjected to a screen against the D10 and FAC8 strains of $P$. falciparum, which confirmed lycorine as the most active compound in the mini-panel $\left(\mathrm{IC}_{50} \mathrm{~S}\right.$ of 0.6 and $0.7 \mu \mathrm{g} / \mathrm{mL}$, respectively) [23]. It was markedly more active than the other three lycorane representatives: seven times more than sternbergine (11), ten times more than anhydrolycorin-6-one (10), and almost fifty times more than 1-O-acetylnorpluviine (12) [23]. It was also demonstrated via the BL6 cytotoxicity evaluation that lycorine $\left(\mathrm{IC}_{50}\right.$ of $\left.1.8 \mathrm{\mu g} / \mathrm{mL}\right)$ was the only alkaloid in the panel with an SI (average 3.0) in favor of antiplasmodial activity, with the others being shown to be potent cytotoxic agents [23]. By contrast, the standard malarial drug chloroquine, in the same instance, exhibited vastly superior SI values of 10450 and 2090, respectively [23].

\section{Amaryllis L.}

With only two verifiable species, Amaryllis belladonna L. and Amaryllis paradisicola Snijman, to its credit, Amaryllis is one of the smallest genera of the Amaryllideae tribe [13]. Although a significant number of alkaloids have been identified in A. belladonna [20], it is only recently that extractives from the plant have been screened for possible antiplasmodial effects [24]. In the event, two lycorane analogs from a MeOH bulb extract following physical and spectroscopic analyses were identified as hippadine (9) and acetylcaranine (13), respectively [24]. The adjoining screen 
- Table 1 Antiplasmodial activities of natural lycorane alkaloids of the Amaryllidaceae.

\begin{tabular}{|c|c|c|c|c|}
\hline Alkaloid (no.) & Plant source & P. falciparum strain ${ }^{\mathrm{a}}$ & Activity, $\mathrm{IC}_{50}(\mu \mathrm{g} / \mathrm{mL})^{\mathrm{b}}$ & Reference \\
\hline \multirow[t]{19}{*}{ Lycorine (1) } & Crinum amabile & D-6 & $\mathrm{ED}_{50}$ of $0.32 \mu \mathrm{g} / \mathrm{mL}$ & [14] \\
\hline & Hymenocallis littoralis & D-6 & Not active & [32] \\
\hline & C. amabile & $W-2$ & $\mathrm{ED}_{50}$ of $0.30 \mu \mathrm{g} / \mathrm{mL}$ & [14] \\
\hline & H. littoralis & $W-2$ & Not active & [32] \\
\hline & Crinum stuhlmannii & NF54 & Not active & [17] \\
\hline & Crinum macowanii & NF54 & 0.34 & [15] \\
\hline & Crinum kirkii & NF54 & Not active & [18] \\
\hline & Narcissus broussonetii & NF54 & Not active & [29] \\
\hline & Zephyranthes citrina & K1 & Not active & [33] \\
\hline & Narcissus tazetta & K1 & 0.379 & {$[28]$} \\
\hline & C. kirkii & K1 & Not active & [18] \\
\hline & N. broussonetii & $\mathrm{K} 1$ & Not active & [29] \\
\hline & Crinum bulbispermum & FCR-3 & 0.029 & [16] \\
\hline & Brunsvigia littoralis & D10 & 0.62 & {$[22]$} \\
\hline & Brunsvigia radulosa & D10 & 0.60 & [23] \\
\hline & B. littoralis & FAC8 & 0.70 & [22] \\
\hline & B. radulosa & FAC8 & 0.70 & [23] \\
\hline & N. tazetta & T9.96 & 1.026 & {$[28]$} \\
\hline & Pancratium canariense & $\mathrm{F}-32$ & 0.037 & [31] \\
\hline \multirow[t]{3}{*}{ Kirkine (2) } & C. stuhlmannii & NF54 & Not active & [17] \\
\hline & C. kirkii & NF54 & Not active & [18] \\
\hline & C. kirkii & K1 & Not active & [18] \\
\hline 9-O-Demethylpluviine (3) & C. stuhlmannii & NF54 & Not active & [17] \\
\hline \multirow[t]{2}{*}{ 1-O-Acetyllycorine (4) } & C. kirkii & NF54 & Not active & [18] \\
\hline & C. kirkii & K1 & Not active & [18] \\
\hline \multirow[t]{2}{*}{ 2-O-Acetyllycorine (5) } & C. kirkii & NF54 & Not active & [18] \\
\hline & C. kirkii & K1 & Not active & [18] \\
\hline \multirow[t]{4}{*}{ 1,2-O-Diacetyllycorine (6) } & B. littoralis & D10 & 1.0 & {$[22]$} \\
\hline & B. littoralis & FAC8 & 1.0 & [22] \\
\hline & C. kirkii & NF54 & Not active & [18] \\
\hline & C. kirkii & K1 & Not active & [18] \\
\hline \multirow[t]{3}{*}{ Zephyranthine (7) } & Cyrtanthus elatus & NF54 & Not active & {$[25]$} \\
\hline & C. kirkii & NF54 & Not active & [18] \\
\hline & C. kirkii & K1 & Not active & [18] \\
\hline \multirow[t]{3}{*}{ 1,2-O-Diacetylzephyranthine (8) } & C. elatus & NF54 & Not active & {$[25]$} \\
\hline & C. kirkii & NF54 & Not active & [18] \\
\hline & C. kirkii & K1 & Not active & [18] \\
\hline \multirow[t]{2}{*}{ Hippadine (9) } & Crinum erubescens & $\mathrm{Dd} 2$ & Not active & [19] \\
\hline & Amaryllis belladonna & $\mathrm{Dd} 2$ & Not active & {$[24]$} \\
\hline \multirow[t]{2}{*}{ Anhydrolycorin-6-one (10) } & B. radulosa & D10 & 6.1 & [23] \\
\hline & B. radulosa & FAC8 & 6.4 & [23] \\
\hline \multirow[t]{2}{*}{ Sternbergine (11) } & B. radulosa & D10 & 3.9 & [23] \\
\hline & B. radulosa & FAC8 & 4.8 & [23] \\
\hline \multirow[t]{2}{*}{ 1-O-Acetylnorpluviine (12) } & B. radulosa & D10 & 28.3 & [23] \\
\hline & B. radulosa & FAC8 & 34.2 & [23] \\
\hline Acetylcaranine (13) & A. belladonna & $\mathrm{Dd} 2$ & 1.1 & ${ }^{[24]}$ \\
\hline
\end{tabular}


- Table 1 Continued

\begin{tabular}{|c|c|c|c|c|}
\hline Alkaloid (no.) & Plant source & P. falciparum strain ${ }^{\mathrm{a}}$ & Activity, $\mathrm{IC}_{50}(\mu \mathrm{g} / \mathrm{mL})^{\mathrm{b}}$ & Reference \\
\hline \multirow[t]{3}{*}{ Ungeremine (14) } & Narcissus angustifolius & NF54 & Not active & [27] \\
\hline & N. angustifolius & K1 & Not active & {$[27]$} \\
\hline & Phaedranassa dubia & K1 & 0.088 & [34] \\
\hline \multirow[t]{2}{*}{ Vasconine (15) } & N. angustifolius & NF54 & Not active & [27] \\
\hline & N. angustifolius & K1 & Not active & [27] \\
\hline \multirow[t]{3}{*}{ Pseudolycorine (16) } & N. angustifolius & NF54 & Not active & [27] \\
\hline & N. angustifolius & K1 & Not active & {$[27]$} \\
\hline & P. dubia & K1 & 0.24 & [34] \\
\hline Dihydrolycorine (17) & Galanthus trojanus & P. falciparum & 16.52 & [30] \\
\hline $\begin{array}{l}\text { 1-O-Acetyldihydromethyl- } \\
\text { pseudolycorine- } N \text {-oxide (18) }\end{array}$ & G. trojanus & P. falciparum & $>20$ & {$[30]$} \\
\hline Galanthine (43) & Z. citrina & K1 & 0.2 & [33] \\
\hline Narcissidine (44) & Z. citrina & K1 & Not active & [33] \\
\hline Zefbetaine (45) & P. dubia & K1 & $>4$ & [34] \\
\hline \multirow[t]{2}{*}{ Ungiminorine (46) } & \multirow[t]{2}{*}{ Lycoris traubii } & FCR-3 & Not tested & {$[35]$} \\
\hline & & K1 & Not tested & [35] \\
\hline \multirow{2}{*}{$\begin{array}{l}\text { 1-O-(3'S)-Hydroxybutanoyl } \\
\text { lycorine (47) }\end{array}$} & \multirow[t]{2}{*}{ L. traubii } & FCR-3 & 0.45 & [35] \\
\hline & & K1 & 0.60 & [35] \\
\hline \multirow[t]{2}{*}{ 5,6-Dehydrolycorine (52) } & \multirow[t]{2}{*}{ Lycoris radiata } & W-2 & 0.54 & [36] \\
\hline & & D-6 & 0.66 & [36] \\
\hline
\end{tabular}

against strain Dd2 was insightful as it showed that only the latter $\left(\mathrm{IC}_{50}\right.$ of $1.1 \mu \mathrm{g} / \mathrm{mL}$ ) was active [24]. Acetylcaranine (13) ( Fig. 1), in the same instance, was far less active $\left(I_{50}\right.$ of $\left.17.5 \mu \mathrm{g} / \mathrm{mL}\right)$ against the human ovarian A2780 cancer cell line, indicating that its detrimental effects were not purely out of cell-based toxicity [24]. By contrast the fully unsaturated analog hippadine (9) proved to be ineffective against both the plasmodial pathogen as well as the cancer cell [24].

\section{Cyrtanthus W. Aiton}

The genus Cyrtanthus is worthy of consideration on its own since it, by itself, constitutes the African tribe Cyrtantheae [13]. Although as many as 60 different species are identifiable for these attractive ornamental plants, which inhabit both summer and winter rainfall regions of southern Africa, Cyrtanthus elatus (Jacq.) Traub remains the only species that has, to date, been examined for antiplasmodial lycorane alkaloid components [25]. In the event, the $\alpha$-dihydro analogs zephyranthine (7) and 1,2-O-diacetylzephyranthine (8) were identified in ethanolic bulb extracts of the plant, but were shown to be inactive against the $P$. falciparum strain NF54 compared to the reference standard chloroquine $\left(\mathrm{IC}_{50}\right.$ of $0.004 \mu \mathrm{g} / \mathrm{mL}$ ) [25].

\section{Narcissus L.}

The genus Narcissus belongs to the tribe Narcisseae, wherein it is accompanied by Sternbergia Waldst. \& Kitaibel and Lapiedra Lag. [13]. It is the largest genus of the tribe and instantly recognizable for its attractive floral characteristics [13]. There is also a long and rich association of Narcissus plants with traditional systems of medicine that can be dated to biblical times and even before [26]. Chemical studies of Narcissus angustifolius Curt. led to the identification of the three lycorane alkaloid constituents, ungeremine (14), vasconine (15), and pseudolycorine (16) [27]. Using the sensitive and resistant $P$. falciparum strains NF54 and K1, respectively, to probe for antiplasmodial activity it was shown that none of these targets exhibited any activities when compared to the artemisinin control $\left(\mathrm{IC}_{50} \mathrm{~S}\right.$ of 0.004 and $0.003 \mu \mathrm{g} / \mathrm{mL}$, respectively) [27]. Not long after this study, Narcissus tazetta L. was part of a collection of Amaryllidaceae plants whose EtOH bulb isolates were examined for possible effects against the chloroquine-resistant $\mathrm{K} 1$ strain as well as the chloroquine-sensitive T9.96 strain of $P$. falciparum [28]. The parent compound lycorine (1) was the only alkaloid of the lycorane group identified and subsequently shown to be active against both strains of the pathogen with $\mathrm{IC}_{50} \mathrm{~S}$ of 0.379 and $1.026 \mu \mathrm{g} / \mathrm{mL}$, respectively ( $\bullet$ Table 1 ) [28]. The standards mefloquine and chloroquine in the same instance exhibited $\mathrm{IC}_{50}$ values of 3.94 and $6.06 \mathrm{\mu g} / \mathrm{mL}$, resepectively, against the $\mathrm{K} 1$ strain [28]. Furthermore, responses to both pathogens were 


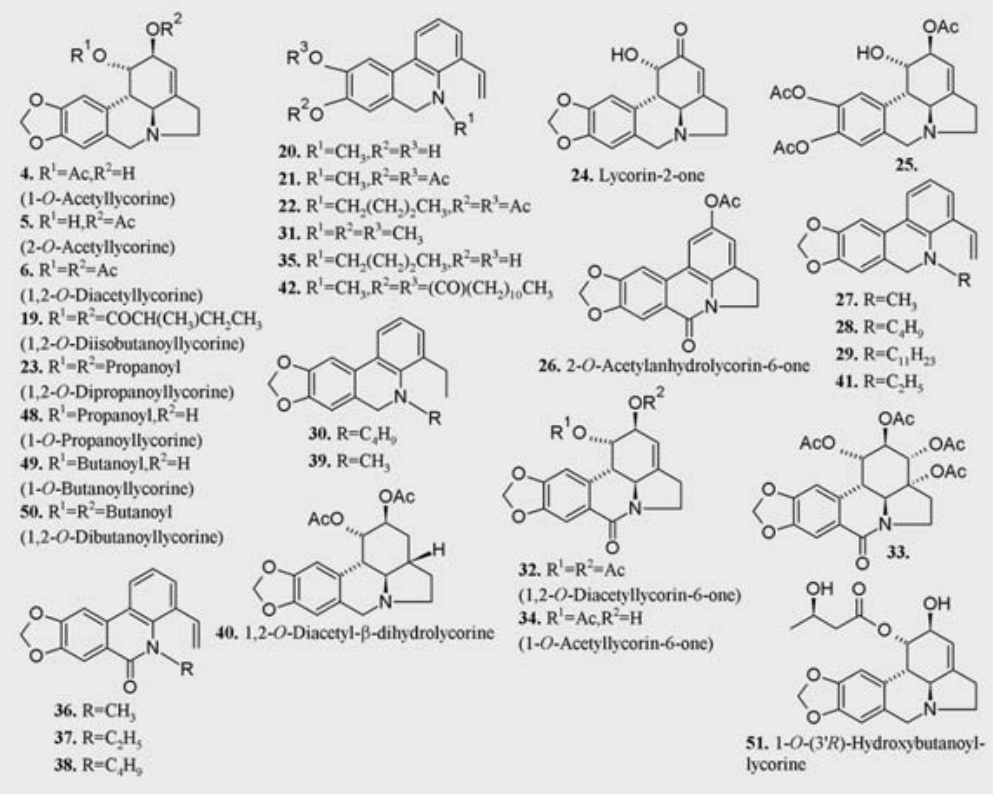

- Fig. 2 Semisynthetically derived lycorane alkaloids that have been screened for antiplasmodial effects.

found to be dose-dependent on lycorine such that at concentrations of $5.0,1.0,0.2$, and $0.04 \mu \mathrm{g} / \mathrm{mL}$ the corresponding growth inhibitory percentages of $\mathrm{K} 1$ cells were $97.53,95.38,44.78$, and $18.33 \%$, respectively [28]. Similar observations were made for the T9.96 strain, wherein the inhibition of cells was $94.80,89.60$, 33.45 , and $10.28 \%$, respectievly, at equimolar concentrations [28]. The Moroccan representative Narcissus broussonetii Lag. was the target of a study carried out to establish its antiprotozoal constituents [29]. The phytochemical component of the work identified lycorine (1) as the sole representative of the lycorane alkaloid group, whilst the subsequent antiplasmodial screening tests revealed that it was inactive against both NF54 and K1 strains of P. falciparum [29].

\section{Galanthus L.}

Galanthus belongs to the tribe Galantheae, which together with the tribes Narcisseae and Pancratieae are the three tribes of the Amaryllidaceae that occur around the Mediterranean region [13]. With over 20 representative species, Galanthus is the largest genus of the tribe Galantheae, which also has Leucojum L. and Acis Salisb. as its other members [13]. A single study of this genus involving whole plants of the Turkish representative Galanthus trojanus A.P.Davis \& Özhatay led to the isolation of two lycorane alkaloid structures, which were identified as dihydrolycorine (17) and 1-O-acetyldihydromethylpseudolycorine- $\mathrm{N}$-oxide (18) [30]. Of the two compounds, only dihydrolycorine exhibited significant antiplasmodial activity against $P$. falciparum $\left(\mathrm{IC}_{50}\right.$ of $16.52 \mu \mathrm{g} /$ $\mathrm{mL}$ ), although this was relatively weak considering that chloroquine, in the same instance, was over 200 times more potent (IC 50 of $0.065 \mu \mathrm{g} / \mathrm{mL}$ ) [30]. 1-O-Acetyldihydromethylpseudolycorine- $N$-oxide (18) ( $\bullet$ Fig. 1 ) proved to be far less effective $\left(I_{50}\right.$
$>20 \mu \mathrm{g} / \mathrm{mL}$ ) [30]. In accompaniment of the screen against the protozoal parasite, both compounds were subjected to a cytotoxicity evaluation against $\mathrm{KB}$ epidermoid cells, but were shown to exhibit minimal effects $\left(\mathrm{IC}_{50} \mathrm{~s}>50 \mu \mathrm{g} / \mathrm{mL}\right)$ [30]. This suggested that the antiplasmodial activity of dihydrolycorine, albeit mild activity, was a consequence of effects on the pathogen as opposed to cell-based effects [30].

\section{Pancratium Dill. ex L.}

Pancratium and Vagaria Herb. are the two genera that make up the Pancratieae tribe [13]. With over 20 known species, Pancratium is by far the larger of the two [13]. Lycorine (1) was identified in EtOH bulb extracts of the "Canary sea daffodil" Pancratium canariense Ker Gawl. [31]. It was then used to prepare a library of 26 different analogs, which were submitted for the screen against the F-32 Tanzania strain of $P$. falciparum, from which some insightful details of the antimalarial lycorane pharmacophore emerged [31]. Despite this significant structural diversity, none of the compounds tested were able to improve on the activity of the parent lycorine (1) $\left(\mathrm{IC}_{50}\right.$ of $\left.0.037 \mu \mathrm{g} / \mathrm{mL}\right)$, so much so that even the second most active compound in the library, 1,2-O-diacetyllycorine (6), was nearly three times less effective $\left(I_{50}\right.$ of $\left.0.097 \mu \mathrm{g} / \mathrm{mL}\right)$ [31]. Furthermore, only five other analogs, including 1-O-acetyllycorine (4), 1,2-O-diisobutanoyllycorine (19) as well as three secoanhydro analogs (20-22) ( $\bullet$ Fig. 2), exhibited submicromolar activities, with $\mathrm{IC}_{50}$ values of around $0.3 \mu \mathrm{g} / \mathrm{mL}$, respectively [31]. A further nine analogs (23-31) exhibited $I C_{50}$ s that were between 1 and $5 \mu \mathrm{g} / \mathrm{mL}$ [31]. Of the remaining compounds, eight (32-39) had $\mathrm{IC}_{50}$ values greater than $40 \mathrm{\mu g} / \mathrm{mL}$, whilst intermediate indices of between $13-29 \mu \mathrm{g} / \mathrm{mL}$ were detected for the others (4042 ) in the library ( $\bullet$ Table 2) [31]. 
- Table 2 Antiplasmodial activities of synthetically derived lycorane analogs.

\begin{tabular}{|c|c|c|c|}
\hline Alkaloid (no.) & $\begin{array}{l}\text { P. falciparum } \\
\text { strain }\end{array}$ & $\begin{array}{l}\text { Activity, } \\
\mathrm{IC}_{50}(\mu \mathrm{g} / \mathrm{mL})\end{array}$ & $\begin{array}{l}\text { Refer- } \\
\text { ence }\end{array}$ \\
\hline \multirow[t]{3}{*}{ 1-O-Acetyllycorine (4) } & $F-32$ & 0.30 & [31] \\
\hline & K1 & 0.36 & [35] \\
\hline & FCR-3 & 0.30 & [35] \\
\hline \multirow[t]{2}{*}{ 2-O-Acetyllycorine (5) } & K1 & 8.21 & [35] \\
\hline & FCR-3 & Not active & [35] \\
\hline \multirow[t]{3}{*}{ 1,2-O-Diacetyllycorine (6) } & $\mathrm{F}-32$ & 0.097 & [31] \\
\hline & K1 & 7.60 & [35] \\
\hline & FCR-3 & Not active & [35] \\
\hline $\begin{array}{l}\text { 1,2-O-Diisobutanoyllycorine } \\
\text { (19) }\end{array}$ & $F-32$ & 0.27 & [31] \\
\hline (20) & $\mathrm{F}-32$ & 0.28 & [31] \\
\hline (21) & $\mathrm{F}-32$ & 0.30 & [31] \\
\hline (22) & $F-32$ & 0.30 & [31] \\
\hline \multirow{3}{*}{$\begin{array}{l}\text { 1,2-O-Dipropanoyllycorine } \\
\text { (23) }\end{array}$} & $F-32$ & 1.08 & [31] \\
\hline & K1 & 4.20 & [35] \\
\hline & FCR-3 & Not active & [35] \\
\hline Lycorin-2-one (24) & $\mathrm{F}-32$ & 4.19 & [31] \\
\hline (25) & $\mathrm{F}-32$ & 3.37 & [31] \\
\hline $\begin{array}{l}\text { 2-O-Acetylanhydrolycorin- } \\
\text { 6-one (26) }\end{array}$ & $F-32$ & 2.97 & [31] \\
\hline (27) & $F-32$ & 3.00 & [31] \\
\hline (28) & $\mathrm{F}-32$ & 2.98 & [31] \\
\hline (29) & $F-32$ & 3.00 & [31] \\
\hline (30) & $F-32$ & 2.29 & [31] \\
\hline (31) & $F-32$ & 3.47 & [31] \\
\hline $\begin{array}{l}\text { 1,2-O-Diacetyllycorin- } \\
\text { 6-one (32) }\end{array}$ & $F-32$ & $>40$ & [31] \\
\hline (33) & $\mathrm{F}-32$ & $>40$ & [31] \\
\hline 1-0-Acetyllycorin-6-one (34) & $\mathrm{F}-32$ & $>40$ & [31] \\
\hline (35) & $\mathrm{F}-32$ & $>40$ & [31] \\
\hline (36) & $\mathrm{F}-32$ & $>40$ & [31] \\
\hline (37) & $F-32$ & $>40$ & [31] \\
\hline (38) & $\mathrm{F}-32$ & $>40$ & [31] \\
\hline (39) & $\mathrm{F}-32$ & $>40$ & [31] \\
\hline $\begin{array}{l}\text { 1,2-O-Diacetyl- } \beta \text { - } \\
\text { dihydrolycorine (40) }\end{array}$ & $F-32$ & 13.00 & [31] \\
\hline (41) & $\mathrm{F}-32$ & 23.9 & [31] \\
\hline (42) & $\mathrm{F}-32$ & 29.0 & [31] \\
\hline \multirow[t]{2}{*}{ 1-O-Propanoyllycorine (48) } & K1 & 0.37 & [35] \\
\hline & FCR-3 & 0.30 & [35] \\
\hline \multirow[t]{2}{*}{ 1-O-Butanoyllycorine (49) } & K1 & 0.41 & [35] \\
\hline & FCR-3 & 0.32 & [35] \\
\hline \multirow{2}{*}{$\begin{array}{l}\text { 1,2-O-Dibutanoyllycorine } \\
(50)\end{array}$} & K1 & 0.67 & [35] \\
\hline & FCR-3 & 0.53 & [35] \\
\hline \multirow{2}{*}{$\begin{array}{l}\text { 1-O-(3'R)-Hydroxybuta- } \\
\text { noyllycorine (51) }\end{array}$} & K1 & 0.62 & [35] \\
\hline & FCR-3 & 0.49 & [35] \\
\hline
\end{tabular}

\section{Hymenocallis Salisb.}

Hymenocallis belongs to the tribe Hymenocallideae, which is identifiable with the Andean clade of the Amaryllidaceae that also includes the tribes Clinantheae, Eucharideae, Eustephieae, and Stenomesseae [13]. The "Beach spider lily" Hymenocallis littoralis (Jacq.) Salisb. has been investigated for antiplasmodial constituents against the chloroquine-sensitive and chloroquine-resistant P. falciparum strains D-6 and W-2, respectively [32]. Lycorine (1) was the only alkaloid of the lycorane group identified in EtOH bulb extracts, but was shown to be inactive against both strains of the parasite examined [32]. This result is somewhat surprising given that lycorine had in fact earlier been shown to be active against both these strains, with $E D_{50} s$ that were in the region of $0.3 \mu \mathrm{g} /$ $\mathrm{mL}[14]$.

\section{Zephyranthes Herb.}

The genus Zephyranthes belongs to the tribe Hippeastreae whose members largely have a South American distribution [13]. Hippeastrum Herb. and Zephyranthes are the largest genera within this tribe [13]. Phytochemical studies on the aerial parts and bulbs of the Cuban plant Zephyranthes citrina Baker yielded three lycorane compounds whose structures were identified as lycorine (1), galanthine (43), and narcissidine (44) [33]. Of these, only galanthine was mildly active in the screen against $P$. falciparum strain $\mathrm{K} 1\left(\mathrm{IC}_{50}\right.$ of $0.2 \mu \mathrm{g} / \mathrm{mL}$ ) compared to chloroquine $\left(I_{50}\right.$ of $0.04 \mu \mathrm{g} / \mathrm{mL}$ ) ( $\vee$ Table 1) [33]. In two instances prior to this, lycorine was indeed shown to be inactive against the $\mathrm{K} 1$ strain $[18,29]$, although a further study identified it as active $\left(\mathrm{IC}_{50}\right.$ of $\left.0.379 \mu \mathrm{g} / \mathrm{mL}\right)[28]$.

\section{Phaedranassa Herb.}

Phaedranassa belongs to the Eucharideae tribe of the Amaryllidaceae whose members also include Eucahris Planch. \& Lind. (the largest of its genera), Eucrosia Ker Gawl., and Stenomesson Herb. [13]. The phytochemical components of EtOH bulb extracts of Phaedranassa dubia (Kunth) J. F.Macbr. following chromatographic and spectroscopic analyses were identified as ungeremine (14), pseudolycorine (16) ( $\bullet$ Fig. 1), and zefbetaine (45) [34]. The subsequent screen against $P$. falciparum strain $\mathrm{K} 1$ revealed zefbetaine as a mild inhibitor ( $\mathrm{IC}_{50}>4 \mu \mathrm{g} / \mathrm{mL}$ ) [34]. By contrast, ungeremine and pseudolycorine were identified as the most active of this minipanel with $\mathrm{IC}_{50} \mathrm{~S}$ of 0.088 and $0.24 \mu \mathrm{g} / \mathrm{mL}$, respectively [34]. Chloroquine $\left(\mathrm{IC}_{50}\right.$ of $\left.0.045 \mu \mathrm{g} / \mathrm{mL}\right)$, in the same instance, was twice as active as ungeremine [34]. The parallel screen against rat L6 myoblasts revealed only ungeremine to exhibit significant cytotoxicity $\left(\mathrm{IC}_{50}\right.$ of $17.3 \mu \mathrm{g} / \mathrm{mL}$ ) compared to the remaining two compounds whose $\mathrm{IC}_{50}$ values were $>80 \mu \mathrm{g} / \mathrm{mL}$, which served to highlight the selective antiplasmodial activity of pseudolycorine (16) [34].

\section{Lycoris Herb.}

The genus Lycoris belongs to the tribe Lycorideae, which is conspicuous for its distribution through most of Asia, but particularly south and east Asia [13]. Lycoris traubii W.Hayw. and L. radiata (L'Hér.) Herb. are its two species that have been screened for anti- 
plasmodial lycorane alkaloid constituents $[35,36]$. The bulbs and aerial parts of the Japanese plant $L$. traubii yielded lycorine (1), sternbergine (11), ungiminorine (46), and 1-O-(3'S)-hydroxybutanoyllycorine (47) as the representative members of the lycorane alkaloid group [35]. In addition to these, a further eight derivatives were accessed from the parent compound lycorine via synthetic manipulation of the hydroxyl groups at $\mathrm{C}-1$ and $\mathrm{C}-2$, respectively [35]. These included 1-O-acetyllycorine (4), 2-O-acetyllycorine (5) 1,2-O-diacetyllycorine (6), 1,2-O-dipropanoyllycorine (23), 1-O-propanoyllycorine (48), 1-O-butanoyllycorine (49), 1,2$O$-dibutanoyllycorine (50), and 1-O-(3'R)-hydroxybutanoyllycorine (51) [35]. Although the subsequent screens against the sensitive (FCR-3) and resistant (K1) strains of $P$. falciparum did not involve lycorine (1), sternbergine (11), or ungiminorine (46), they were nevertheless insightful for the activities of the remaining acylated lycorine derivatives [35]. Overall, good activities were observed for most of these lycorine products in both $P$. falciparum strains, where $\mathrm{IC}_{50}$ values ranged from 0.3 to $8.21 \mu \mathrm{g} / \mathrm{mL}$, with the best activity demonstrated for 1-O-acetyllycorine (4) and 1-Opropanoyllycorine (48) ( $\bullet$ Fig. 2 ) against the FCR-3 strain (both with an $\mathrm{IC}_{50}$ of $0.3 \mu \mathrm{g} / \mathrm{mL}$ ) [35]. No activities were detectable for 2-O-acetyllycorine (5), 1,2-O-diacetyllycorine (6), and 1,2-O-dipropanoyllycorine (23) in the sensitive FCR-3 strain, whilst the remaining compounds 1-O-(3'S)-hydroxybutanoyllycorine (47), 1O-butanoyllycorine (49), 1,2-O-dibutanoyllycorine (50), and 1-O$\left(3^{\prime} R\right)$-hydroxybutanoyllycorine (51) exhibited $\mathrm{IC}_{50}$ s of $0.45,0.32$, 0.53 , and $0.49 \mu \mathrm{g} / \mathrm{mL}$, respectively [35]. Good activities were also observed in the $\mathrm{K} 1$ strain, with the monoesters 1 -O-acetyllycorine (4), 1-O-propanoyllycorine (48), and 1-O-butanoyllycorine (49) shown to be the most effective $\left(\mathrm{IC}_{50} \mathrm{~s}\right.$ of $0.36,0.37$, and $0.41 \mathrm{\mu g} /$ $\mathrm{mL}$, respectively) [35]. 2-O-Acetyllycorine (5), 1,2-O-diacetyllycorine (6), and 1,2-O-dipropanoyllycorine (23), which were inactive in the FCR-3 screen, demonstrated better activities against strain $\mathrm{K} 1$, although their respective $\mathrm{IC}_{50}$ values of $8.21,7.6$, and $4.2 \mu \mathrm{g} / \mathrm{mL}$ ( $\vee$ Table 2 ) were the lowest of all compounds across both sensitive and resistant strains [35]. The remaining three alkaloids, including the two hydroxybutanoyl esters $(47,51)$ as well as the bis-butanoyl ester (50), were quite active against the $\mathrm{K} 1 \mathrm{strain}$ with $\mathrm{IC}_{50}$ values of $0.6,0.62$, and $0.67 \mu \mathrm{g} / \mathrm{mL}$, respectively [35]. In order to establish whether their antiplasmodial activities were a consequence of general cytotoxicity, a co-screen of the nine alkaloids was also carried out against the MRC-5 human diploid embryonic cell line [35]. In the event, the best SI values were obtained for the bis-butanoyl ester (50) (21.7 and 27.5 for K1 and FCR-3, respectively) [35]. In context, however, none of the nine compounds were able to match the $\mathrm{SI}$ values determined for the artemisinin standard, which was $>7000$ in either case [35].

The remaining work on the Asian genus Lycoris involved the in vitro examination of bulb ethanolic extracts of Lycoris radiata for antiplasmodial constituents in drug-sensitive (W-2) and drug-resistant (D-6) cultures of $P$. falciparum [36]. In the event, the single lycorane alkaloid was identified via its physical and spectroscopic data as 5,6-dehydrolycorine (52) [36]. This cationic compound (52) ( $\triangleright$ Fig. 1) proved to be active against both strains, with $I C_{50}$ values of 0.54 and $0.66 \mu \mathrm{g} / \mathrm{mL}$, respectively [36]. A concurrent screen against seven human cancer cells showed 5,6-dehydrolycorine (52) to also be a cytotoxic agent, with a mean $\mathrm{IC}_{50}$ of
$3.06 \mu \mathrm{g} / \mathrm{mL}$ [36]. It was extrapolated from the SI values that its cytotoxic effects may be a mitigating factor in the observed antiplasmodial activities against both strains [36].

\section{Structure-activity Relationships}

Interestingly, submicromolar antiplasmodial activities were detected for both natural lycorane alkaloids of the Amaryllidaceae as well as analogs accessed via semisynthetic means ( $\vee$ Tables 1 and 2). These reflected that the parent compound lycorine (1) was, overall, the most potent antiplasmodial agent. Its best activities were seen in the FCR-3 $\left(\mathrm{IC}_{50}\right.$ of $\left.0.029 \mu \mathrm{g} / \mathrm{mL}\right)$ and F-32 $\left(\mathrm{IC}_{50}\right.$ of $0.037 \mu \mathrm{g} / \mathrm{mL}$ ) strains, respectively $[16,31]$. The other two compounds that stood out were also both natural, 1,2-O-diacetyllycorine (6) ( $\mathrm{IC}_{50}$ of $0.097 \mu \mathrm{g} / \mathrm{mL}$ against the $\mathrm{F}-32$ strain) and ungeremine (14) $\left(\mathrm{IC}_{50}\right.$ of $0.088 \mu \mathrm{g} / \mathrm{mL}$ against the $\mathrm{K} 1$ strain) [31, 34]. Given that the A-ring of the lycorane template is, by convention, a 1,2,4,5-tetrasubstituted aryl system, little can be achieved by way of further structural modification [8]. This is in contrast to the crinane alkaloids, who, like lycorane alkaloids, are also a major alkaloid group of the Amaryllidaceae, where a C-7 methoxyl group is common for many of its representatives [8]. Whilst the A-ring methylenedioxy moiety is a mainstay of lycorane alkaloids, several of its members, such as pseudolycorine (16), are discernible, wherein this feature has been modified [8]. It appears that there may be some modulating role of the methylenedioxy group in the antiplasmodial effects of these alkaloids. To this extent, pseudolycorine (16), which possesses methoxy and hydroxy groups at C-8 and C-9, respectively, proved to be slightly more effective against the $\mathrm{K} 1$ strain $\left(\mathrm{IC}_{50}\right.$ of $\left.0.24 \mu \mathrm{g} / \mathrm{mL}\right)$ compared to lycorine $\left(\mathrm{IC}_{50}\right.$ of $0.379 \mu \mathrm{g} / \mathrm{mL}$ ) $[28,34]$. This effect was quite dramatic for the NF54 strain where the roles were reversed with lycorine $\left(\mathrm{IC}_{50}\right.$ of $0.34 \mu \mathrm{g} / \mathrm{mL}$ ) and was shown to completely outdo the inactive pseudolycorine $[15,27]$. Similarly, for the betaine structure pair ungeremine (14) and zefbetaine (45), the former (IC 50 of $0.088 \mu \mathrm{g} / \mathrm{mL}$ ) with an intact methylenedioxy ring system proved to be far superior to the latter $\left(\mathrm{IC}_{50}>4 \mu \mathrm{g} / \mathrm{mL}\right)$ in cultures of $\mathrm{K} 1$ cells [34].

If the A- ring was constrained in terms of the options available for further manipulation, the B-ring, which is positioned at the confluence of both rings $A$ and $C$ as well as rings $A$ and $D$, was even more so the case [8]. Although C-4a and C-10b can also succumb to modification, this can only ensue via loss of the 1,2-dihydroxy groups and concomitant aromatization of the C-ring, as seen via hippadine (9), anhydrolycorin-6-one (10), and ungeremine (14) [8]. The nitrogen atom as well as C-6 are thus the sites most amenable towards synthetic maneuvers [8]. The C-6 methylene group is an important component of the lycorane antiplasmodial pharmacophore since oxidation, as in the case of 1,2-O-diacetyllycorin-6-one (32) and 1-O-acetyllycorin-6-one (34), was detrimental [31]. Both of these compounds exhibited $I C_{50} \mathrm{~s}>40 \mu \mathrm{g} / \mathrm{mL}$ in the $\mathrm{F}-32$ strain compared to their vastly superior unoxidized variants 1,2-O-diacetyllycorine (6) and 1-O-acetyllycorine (4) $\left(\mathrm{IC}_{50} \mathrm{~S}\right.$ of 0.097 and $0.3 \mu \mathrm{g} / \mathrm{mL}$, resepectively) [31]. Interestingly, in the case of 1,2-O-diacetyllycorin-6-one (32) and 1-O-acetyllycorin-6-one (34), the oxo group, as expected, projects out of the ring, whereas in 5,6-dehydrolycorine (52), the double bond has an internal dis- 
position [31]. This isomerization, which also serves to quarternize the nitrogen atom, appears to have a slight modulatory effect since 5,6-dehydrolycorine (52) exhibited $\mathrm{IC}_{50} \mathrm{~S}$ of 0.54 and $0.66 \mu \mathrm{g} / \mathrm{mL}$ against the $\mathrm{W}-2$ and D-6 strains, respectively, compared to lycorine (1) in the same strains $\left(E_{50} \mathrm{~s}\right.$ of 0.30 and $0.32 \mu \mathrm{g} / \mathrm{mL}$, respectively) $[14,36]$.

Of the four rings that make up the lycorane skeleton, the C-ring affords the most ample opportunities for further functionalization [8]. Not surprsingly, the majority of targets examined for antiplasmodial effects, to date, exploit this feature as leverage. Firstly, the C-1 and C-2 dihydroxy groups are excellent scaffolds for both mono- and disubstitution directed probes [8]. Chemo/regioselective oxidation is also possible at these positions taking into account the allylic nature of the C-2 hydroxyl group [8]. Secondly, the double bond can be modified via either oxidative or reductive means, both stereo- and non-stereoselectively [8]. Thirdly, as mentioned above, it is possible to reverse the polarity at C-4a and C-10b, albeit indirectly, via dehydration of the C-1 and C-2 dihydroxy groups [8]. In spite of these options available for C-ring differentialization, the parent lycorine (1), as indicated above, proved to be the most active of the lycorane compounds examined ( $\triangleright$ Tables 1 and 2 ). The majority of modified C-ring compounds probed were acyl derivatives, of which 1,2-O-diacetyllycorine (6) $\left(\mathrm{IC}_{50}\right.$ of $0.097 \mu \mathrm{g} / \mathrm{mL}$ against the $\mathrm{F}-32$ strain) was the most potent [31]. Nonetheless, this acylated compound was nearly three times less active than lycorine itself $\left(\mathrm{IC}_{50}\right.$ of $0.037 \mu \mathrm{g} / \mathrm{mL}$ ) in the same strain [31]. Similarly, $I_{50}$ values of 0.6 and $0.7 \mu \mathrm{g} / \mathrm{mL}$ were determined for lycorine in the D10 and FAC8 strains, respectively, which were markedly better than those ascertained for 1,2-O-diacetyllycorine $\left(\mathrm{IC}_{50}\right.$ of $1.0 \mu \mathrm{g} / \mathrm{mL}$ against both strains, respectively) [22,23]. Lycorine also proved to be much more active against the $\mathrm{K} 1 \mathrm{strain}\left(\mathrm{IC}_{50}\right.$ of $\left.0.379 \mu \mathrm{g} / \mathrm{mL}\right)$ than 1,2-O-diacetyllycorine $\left(\mathrm{IC}_{50}\right.$ of $\left.7.60 \mu \mathrm{g} / \mathrm{mL}\right)[28,35]$. These results higlighted that small polar groups with hydrogen bond donor-acceptor capabilities are preferred at C- 1 and C-2. The acyl derivatives would obviously forfeit the hydrogen bond donor functions. Varying the chain length of the acyl derivative proved to be attenuative gauging from activities in the $\mathrm{F}-32$ strain for 1,2-O-diacetyllycorine (6) and 1,2-O-dipropanoyllycorine (23) $\left(\mathrm{IC}_{50} \mathrm{~S}\right.$ of 0.097 and $1.08 \mu \mathrm{g} / \mathrm{mL}$, respectively) [31]. Mono-acylation was also accompanied by modulatory effects, as seen for lycorine (1) against 1-O-acetyllycorine (4) in the F-32, K1, and FCR-3 strains, where the former exhibited $I_{50}$ of $0.037,0.379$, and $0.029 \mu \mathrm{g} /$ $\mathrm{mL}$, respectively $[16,28,31]$. $I C_{50}$ s determined for the latter were $0.30,0.36$, and $0.30 \mu \mathrm{g} / \mathrm{mL}$, respectively $[31,35]$. There does not appear to be a significant influence by the chain length of the $\mathrm{C}-1$ acyl analog based on the activities of 1-O-acetyllycorine (4), 1-Opropanoyllycorine (48), and 1-O-butanoyllycorine (49) against the $\mathrm{K} 1$ and FCR-3 strains where the mean $\mathrm{IC}_{50}$ values were $0.33,0.34$, and $0.37 \mu \mathrm{g} / \mathrm{mL}$, respectively [35]. Furthermore, any internal adjustment to the acyl group itself was shown to be significant, as the hydroxy esters 1-O-(3'S)-hydroxybutanoyllycorine (47) and 1$O-\left(3^{\prime} R\right)$-hydroxybutanoyllycorine (51) exhibited mean $I_{50} \mathrm{~S}$ of 0.53 and $0.56 \mu \mathrm{g} / \mathrm{mL}$ against the above two strains compared to the straight-chain ester 1-O-butanoyllycorine (49) (mean IC 50 of $0.37 \mu \mathrm{g} / \mathrm{mL}$ ) [35]. Selective acylation at the C-2 position was deleterious, as 2-O-acetyllycorine (5) was inactive against the FCR-3 strain and had an $\mathrm{IC}_{50}$ of $8.21 \mu \mathrm{g} / \mathrm{mL}$ in the $\mathrm{K} 1$ strain [35]. Removal of the $\mathrm{C}-2$ functionality was also an exacerbative operation since the resulting products such as kirkine (2), 9-O-demethylpluviine (3), 1-O-acetylnorpluviine (12), and acetylcaranine (13) all suffered the same fate in the NF54, K1, D10, FAC8, and Dd2 strains $[17,18,23,24]$. The stereochemical disposition of the C-1 and C-2 substituents is also worthy of mention considering the data described for zephyranthine (7) and 1,2-O-diacetylzephyranthine (8) $[18,25]$. These compounds, which have the C-2 substituent in the unusual $\alpha$-orientation, were both inactive against the NF54 and $\mathrm{K} 1$ strains $[18,25]$. The corresponding compounds dihydrolycorine (17) and 1,2-O-diacetyl- $\beta$-dihydrolycorine (40), wherein the $\mathrm{C}-2$ substituents are with the normal $\beta$-orientation, were active, albeit mildly, against $P$. falciparum $\left(\mathrm{IC}_{50}\right.$ of $\left.16.52 \mu \mathrm{g} / \mathrm{mL}\right)$ and strain F-32 (IC 50 of $13.00 \mu \mathrm{g} / \mathrm{mL})$, respectively [30,31]. The merit of these comparisons can, however, be called into question given that the antiplasmodial activities were reported from different strains of the parasite $[18,25,30,31]$. Oxidation of the C-ring hydroxyl groups is also deemed as a deleterious maneuvers based on the activity of lycorin-2-one $(24)\left(\mathrm{IC}_{50}\right.$ of $\left.4.19 \mu \mathrm{g} / \mathrm{mL}\right)$ in the $\mathrm{F}-32$ strain, against which lycorine (1) was over 100 times more potent $\left(\mathrm{IC}_{50}\right.$ of $0.037 \mu \mathrm{g} / \mathrm{mL}$ ) [31]. For the natural lycorane analogs, the C-ring adopts the inverted quasi-boat conformation with both hydroxyl groups in the pseudo-equatorial disposition [8]. Following oxidation of lycorine to lycorin-2-one, the C-ring, with an additional $\mathrm{sp}^{2}$ center, becomes, as expected, more flattened [8]. The planar nature of $\mathrm{C}-2$ together with the loss of hydrogen bond donor capability of the keto group could thus explain the dramatic loss in activity of lycorin-2-one (24) [31]. Reduction of the double bond was also detrimental since racemic dihydrolycorine (17) exhibited an $\mathrm{IC}_{50}$ of $16.52 \mu \mathrm{g} / \mathrm{mL}$ against $P$. falciparum [30] compared to lycorine (1), which had submicromolar activities against the majority of strains examined ( $\vee$ Table 1 ). Similarly, $1,2-0$-diacetyl- $\beta$-dihydrolycorine (40), a single diastereomer, exhibited an $I C_{50}$ of $13.00 \mu \mathrm{g} / \mathrm{mL}$ in the $\mathrm{F}-32$ strain, well over 100 times less than its unsaturated congener 1,2-O-diacetyllycorine (6) (IC 50 of $0.097 \mu \mathrm{g} / \mathrm{mL}$ ) [31]. In the $\beta$-dihydro product $(40)$, the $C$-ring adopts a near perfect inverted boat conformation with $\mathrm{H}-4$ positioned axially at the bridgehead position of rings $B$ and $C$ [8]. It is clear from this that unsaturation in ring $C$, which produces the quasi-boat conformation, is preferred over saturation [31]. Oxidation of the double bond likewise also serves to exacerbate activity since the 1,2,3,4-tetraacetyl compound (33) exhibited an IC 50 value $>40 \mu \mathrm{g} / \mathrm{mL}$ in the $\mathrm{F}-32$ strain [31]. Interestingly, with both the C-3 and C-4 acetoxy groups in compound (33) equatorially disposed, the C-ring adopts a near perfect boat conformation [31]. This feature together with an additional substitution in ring $C$ could explain the loss in activity for compound (33) [31]. The case where $\mathrm{C}-3$ is oxidized, accompanied by a shift of the double bond to the $\mathrm{C}-4 / \mathrm{C}-11$ positions, also proved to be detrimental since narcissidine (44) was inactive when tested against the K1 strain [33]. There is notable modulation following adjustments to the C-4a and $\mathrm{C}-10 \mathrm{~b}$ centers as mentioned above since the majority of the related compounds screened were far less active than lycorine, including hippadine (9), anhydrolycorin-6-one (10), ungeremine (14), vasconine (15), and zefbetaine (45) ( $>$ Table 1). Nonetheless, ungeremine $\left(\mathrm{IC}_{50}\right.$ of $0.088 \mu \mathrm{g} / \mathrm{mL}$ ) proved to fare better than 
lycorine $\left(\mathrm{IC}_{50}\right.$ of $\left.0.379 \mu \mathrm{g} / \mathrm{mL}\right)$ against the $\mathrm{K} 1$ strain $[28,34]$. The idea that the betaine structure of ungeremine may be bolstering its activity, whilst attractive, is however negated by the fact that the related compound zefbetaine (45), also bearing a betaine structure, exhibited poor effects against the $\mathrm{K} 1$ strain $\left(\mathrm{IC}_{50}\right.$ $>4 \mu \mathrm{g} / \mathrm{mL}$ ) [34]. There has also been considerable interest in the D-ring seco-analogs of lycorine, such as compounds 20-22, 2731, and 36-39 ( Fig. 2), as potential antiplasmodial agents. However, in spite of these diverse efforts, only compounds 2022 exhibited submicromolar activities $\left(\mathrm{IC}_{50} \mathrm{~S}\right.$ of $0.28,0.30$, and $0.3 \mu \mathrm{g} / \mathrm{mL}$, respectively, against strain F-32) [31]. This suggested that the D-ring pyrrolidine moiety is a neccessary component of the lycorane alkaloid antiplasmodial pharmacophore [31].

\section{Mechanistic Insight}

Given that malaria is a life-threatening ailment, a significant body of work has emerged in pharmacology addressing the mechanisms by which antimalarial drugs manifest their action [37]. These drugs have been classified according to the stages at which they intervene in the parasite life cycle [37]. Schizonticide drugs used for causal prophylaxis, such as pyrimethamine and primaquine, act on the primary plasmodial tissue, which, after growth in the liver, develops into active erythrocytes [38]. These drugs can also act on the hypnozoites of $P$. vivax and $P$. ovale, which can produce a relapse of symptoms once reactivated [38]. Blood schizonticides such as chloroquine, quinine, mefloquine, halofantrine, pyrimethamine, sulfadoxine, sulfones, and tetracyclines act on the parasite directly in the blood of the host [38]. Gametocytocide drugs target the parasite during its various sexual stages in the blood, thereby preventing transmission of infection to the insect vector [38]. Chloroquine and quinine are gametocytocidal towards $P$. vivax and $P$. malariae, but not against $P$. falciparum, whilst primaquine is gametocytocidal against all plasmodia, including P. falciparum [38]. Sporontocides such as primaquine and chloroguanide prevent the development of oocysts in the insect, thus obliterating the transmission [38]. At the biochemical level, quinine is known to inhibit nucleic acid and protein synthesis as well as glycolysis in P. falciparum [37]. It can also bind to hemozoin in parasitized erythrocytes [37]. Chloroquine has been shown to accumulate in the food vacuoles of the parasite where it prevents the polymerization of the hemoglobin product heme into hemozoin, thereby eliciting toxicity via the buildup of heme [37]. In relation to primaquine, there is evidence to show that one or more of its metabolic products can inflict significant oxidative damage that perturbs mitochondrial electron transport in the parasite [37]. The pyrimethamine-sulfadoxine combination is known to be synergistic in inhibiting folic acid synthesis [37]. This also lends itself to the fact that there is a differential requirement between host and parasite for nucleic acid precursors involved in growth [37]. Artemisinin, by contrast, produces a toxic free radical when it undergoes an iron-catalyzed cleavage of its endoperoxide bond in the parasite food vacuole [37].

Due to several difficulties attending the study of liver stage plasmodial parasites, the pace of elucidating new biological targets has been relatively slow [39]. Nevertheless, it has been shown that liver stage malarial parasites exhibit a requirement for de novo type II fatty acid biosynthesis (FAS-II), which was previously considered to be essential at the blood stage [39]. It now appears that the FAS-II pathway is, in fact, necessary for the late hepatic stage [39]. As such, the inactivation of critical elongation enzymes such as FabB/F ( $\beta$-ketoacyl-ACP synthase) and FabZ ( $\beta$-hydroxyacyl-ACP dehydratase) in Plasmodium yoelii inhibited the generation of exoerythrocytic merozoites, i.e., the inability to cause a bloodstage infection [39]. Similarly, Plasmodium berghei sporozoites deficient in Fabl (enoyl-ACP reductase) were markedly less infective in mice and failed to complete liver stage development [39]. These findings suggest that the plasmodial FAS-II pathway is indeed an attractive target for malarial drug development [39]. With this in mind, the study of $G$. trojanus identified dihydrolycorine (17) and 1-O-acetyldihydromethylpseudolycorine- $\mathrm{N}$-oxide (18) as antiprotozoal lycorane alkaloids $\left(\mathrm{IC}_{50} \mathrm{~S}\right.$ of 16.52 and $>20 \mu \mathrm{g} / \mathrm{mL}$ against $P$. falciparum, respectively) [30]. The investigation also involved a screen of the compounds against the plasmodial FAS-II enzymes PfFabl, PfFabG, and PfFabZ [30]. In the event, $I C_{50}$ values determined for dihydrolycorine were $>100$, > 100, and $33 \mu \mathrm{g} / \mathrm{mL}$, respectively, compared to those for 1-O-acetyldihydromethylpseudolycorine- $N$-oxide, which were $89,>100$, and $13 \mu \mathrm{g} /$ $\mathrm{mL}$, respectively [30]. The inhibitory activities for both compounds against PfFabZ is noteworthy, but were nevertheless significantly less than that observed for the standard (-)-epigallocatechin gallate $\left(\mathrm{IC}_{50}\right.$ of $\left.0.3 \mu \mathrm{g} / \mathrm{mL}\right)$ [30].

\section{Conclusions}

The plant family Amaryllidaceae via its lycorane alkaloid principles is herein portrayed as a viable platform for drug discovery in the antimalarial arena. Fifty-two compounds embracing both natural and synthetically derived forms were examined against ten different strains of the malaria pathogen $P$. falciparum. Although good activities were detectable across both series of compounds, the natural varieties (lycorine in particular) exhibited better overall activities. These responses were spread out across both chloroquine-sensitive and chloroquine-resistant strains of the parasite. Structure-activity-based studies were insightful in deciphering the elements of the antiplasmodial pharmacophore, which was shown to revolve around an intact tetracylic core, with some allowance being made for substitution in the various rings. Mechanistic probes resolved the lycorane targets as specific enzymes of the plasmodial FAS-II biosynthetic pathways. This review attests to the significant amount of space to pursue in the area since the number of species (20), to date, examined for antiplasmodial lycorane constituents is small compared to the nearly 1000 species known in the family. Given the natural abundance of the parent compound lycorine, its good antiplasmodial activities as well as the ease in which it can be transformed into a variety of active targets, semisynthesis should gain momentum in efforts going forward. Similarly, since the biological targets for these alkaloids have only recently been described, future endeavors are likely to focus heavily on these entities. 


\section{Acknowledgements}

The University of KwaZulu-Natal has made significant contributions towards the research initiatives of the authors.

\section{Conflict of Interest}

The findings described herein are a consolidation of independent research carried out in the laboratories of the authors. As such, none of its content in any shape or form is deemed liable to any other individual or organization.

\section{References}

[1] World Health Organization. World Malaria Report 2018. Geneva: WHO Press; 2018: 1-60

[2] Cowman AF, Healer J, Marapana D, Marsh K. Malaria: biology and disease. Cell 2016; 167: 610-624

[3] Buffet PA, Safeukui I, Deplaine G, Brousse V, Prendki V, Thellier M, Turner GD, Mercereau-Puijalon O. The pathogenesis of Plasmodium falciparum malaria in humans: insights from splenic physiology. Blood 2011; 117: 381-392

[4] Wink M. Medicinal plants: a source of anti-parasitic secondary metabolites. Molecules 2012; 17: 12771-12791

[5] Andrews KT, Fisher G, Skinner-Adams TS. Drug repurposing and human parasitic protozoan diseases. Int J Parasitol Drugs Drug Resist 2014; 4 : 95-111

[6] Schwikkard S, Van Heerden FR. Antimalarial activity of plant metabolites. Nat Prod Rep 2002; 19: 675-692

[7] Kaur K, Jain M, Kaur T, Jain R. Antimalarials from nature. Bioorg Med Chem 2009; 17: 3229-3256

[8] Jin Z, Yao G. Amaryllidaceae and Sceletium alkaloids. Nat Prod Rep 2019. doi:10.1039/c8np00055g

[9] Bastida J, Lavilla R, Viladomat F. Chemical and biological Aspects of Narcissus Alkaloids. In: Cordell GA, ed. The Alkaloids. Amsterdam: Elsevier; 2006: 87-179

[10] Nair J], Wilhelm A, Bonnet SL, van Staden J. Antibacterial constituents of the family Amaryllidaceae. Bioorg Med Chem Lett 2017; 27: 4943-4951

[11] Nair J], van Staden J. Antifungal constituents of the plant family Amaryllidaceae. Phytother Res 2018; 32: 976-984

[12] Nair JJ, van Staden J. Cytotoxicity studies of lycorine alkaloids of the Amaryllidaceae. Nat Prod Commun 2014; 9: 1193-1210

[13] Meerow AW, Snijman DA. Phylogeny of Amaryllidaceae tribe Amaryllideae based on NRDNA ITS sequences and morphology. Am J Bot 2001; 88: $2321-2330$

[14] Likhitwitayawuid K, Angerhofer CK, Chai H, Pezzuto JM, Cordell GA, Ruangrungsi N. Cytotoxic and antimalarial alkaloids from the bulbs of Crinum amabile. J Nat Prod 1993; 56: 1331-1338

[15] Nair J], Machocho AK, Campbell WE, Brun R, Viladomat F, Codina C, Bastida J. Alkaloids from Crinum macowanii. Phytochemistry 2000; 54: 945-950

[16] Griffiths S. Antimalarial compounds from Crinum bulbispermum (M.Sc dissertation). Potchefstroom: North West University; 2004

[17] Machocho A, Chhabra SC, Viladomat F, Codina C, Bastida J. Alkaloids from Crinum stuhlmannii. Planta Med 1998; 64: 679-680

[18] Machocho AK, Bastida J, Codina C, Viladomat F, Brun R, Chhabra SC. Augustamine type alkaloids from Crinum kirkii. Phytochemistry 2004; 65: 3143-3149

[19] Presley CC, Krai P, Dalal S, Su Q, Cassera M, Goetz M, Kingston DGI. New potently bioactive alkaloids from Crinum erubescens. Bioorg Med Chem 2016; 24: 5418-5422
[20] Viladomat F, Bastida J, Codina C, Nair J], Campbell WE. Alkaloids of the South African Amaryllidaceae. In: Pandalai SG, ed. Recent Research Developments in Phytochemistry. Trivandrum: Research Signpost Publishers; 1997: 131-171

[21] Nair J], Bastida J, Codina C, Viladomat F, van Staden J. Alkaloids of the South African Amaryllidaceae: a review. Nat Prod Commun 2013; 8: $1335-1350$

[22] Campbell WE, Nair JJ, Gammon DW, Bastida J, Codina C, Viladomat F, Smith PJ, Albrecht CF. Cytotoxic and antimalarial alkaloids from Brunsvigia littoralis. Planta Med 1998; 64: 91-93

[23] Campbell WE, Nair JJ, Gammon DW, Codina C, Bastida J, Viladomat F, Smith PJ, Albrecht CF. Bioactive alkaloids from Brunsvigia radulosa. Phytochemistry 2000; 53: 587-591

[24] Cho N, Du Y, Valenciano AL, Fernandez-Murga ML, Goetz M, Clement ], Cassera MB, Kingston DGI. Antiplasmodial alkaloids from bulbs of Amaryllis belladonna Steud. Bioorg Med Chem Lett 2018; 28: 40-42

[25] Herrera MR, Machocho AK, Nair J], Campbell WE, Brun R, Viladomat F, Codina C, Bastida J. Alkaloids from Cyrtanthus elatus. Fitoterapia 2001; 72: $444-448$

[26] Kornienko A, Evidente A. Chemistry, biology and medicinal potential of narciclasine and its congeners. Chem Rev 2008; 108: 1982-2014

[27] Labraña ], Machocho AK, Kricsfalusy V, Brun R, Codina C, Viladomat F, Bastida J. Alkaloids from Narcissus angustifolius subsp. transcarpathicus (Amaryllidaceae). Phytochemistry 2002; 60: 847-852

[28] Şener B, Orhan I, Stayavivad J. Antimalarial activity screening of some alkaloids and the plant extracts from Amaryllidaceae. Phytother Res 2003; 17: 1220-1223

[29] De Andrade JP, Pigni NB, Torras-Claveria L, Berkov S, Codina C, Viladomat F, Bastida J. Bioactive alkaloid extracts from Narcissus broussonetii: mass spectral studies. J Pharm Biomed Anal 2012; 70: 13-25

[30] Kaya GI, Sarıkaya B, Onur MA, Somer NU, Viladomat F, Codina C, Bastida J, Lauinger IL, Kaiser M, Tasdemir D. Antiprotozoal alkaloids from Galanthus trojanus. Phytochem Lett 2011; 4: 301-305

[31] Cedrón JC, Gutiérrez D, Flores N, Ravelo AG, Estévez-Braun A. Synthesis and antiplasmodial activity of lycorine derivatives. Bioorg Med Chem 2010: 18: 4694-4701

[32] Lin LZ, Hu SF, Chai HB, Pengsuparp T, Pezzuto JM, Cordell GA, Ruangrungsi $\mathrm{N}$. Lycorine alkaloids from Hymenocallis littoralis. Phytochemistry 1995; 40: 1295-1298

[33] Herrera MR, Machocho AK, Brun R, Viladomat F, Codina C, Bastida J. Crinane and lycorane type alkaloids from Zephyranthes citrina. Planta Med 2001; 67: 191-193

[34] Osorio E], Berkov S, Brun R, Codina C, Viladomat F, Cabezas F, Bastida J. In vitro antiprotozoal activity of alkaloids from Phaedranassa dubia (Amaryllidaceae). Phytochem Lett 2010; 3: 161-163

[35] Toriizuka Y, Kinoshita E, Kogure N, Kitajima M, Ishiyama A, Otoguro K, Yamada H, Omura S, Takayama H. New lycorine-type alkaloid from Lycoris traubii and evaluation of antitrypanosomal and antimalarial activities of lycorine derivatives. Bioorg Med Chem 2008; 16: 10182-10189

[36] Hao B, Shen SF, Zhao QJ. Cytotoxic and antimalarial alkaloids from the bulbs of Lycoris radiata. Molecules 2013; 18: 2458-2468

[37] Müller IB, Hyde JE. Antimalarial drugs: modes of action and mechanisms of parasite resistance. Future Microbiol 2010; 5: 1857-1873

[38] Saifi MA, Beg T, Harrath AH, Altayalan FSH, Al Quraishy S. Antimalaria drugs: mode of action and status of resistance. Afr J Pharm Pharmacol 2013; 7: 148-156

[39] Vaughan AM, O'Neill MT, Tarun AS, Camargo N, Phuong TM, Aly ASI, Cowman AF, Kappe SHI. Type II fatty acid synthesis is essential only for malaria parasite late liver stage development. Cell Microbiol 2009; 11: 506-520 